\title{
Growth and Characterization of Holmium Oxalate Heptahydrate Crystals
}

\author{
Basharat Want, Feroz Dar
}

Solid State Research Laboratory, Department of Physics, University of Kashmir, Srinagar, India.

Email: bawant@kashmiruniversity.ac.in

Received June $30^{\text {th }}, 2012$; revised August $6^{\text {th }}, 2012$; accepted August $28^{\text {th }}, 2012$

\begin{abstract}
Single crystals of holmium oxalate heptahydrate are grown by gel diffusion method using organic agar gel as a medium of growth. The crystals grow in the agar gel with hexagonal morphology having well defined habit faces Powder X-ray diffraction results show that the crystals belong to monoclinic system bearing the space group $\mathrm{P} 2{ }_{1} / \mathrm{c}$ with cell parameters; $a=12.197 \AA, b=11.714 \AA, c=6.479 \AA, \alpha=90^{\circ}, \beta=120.12^{\circ}, \gamma=90^{\circ}, \mathrm{V}=799.6 \AA^{3}$. Fourier transform Infra-red spectrum of the crystals shows the presence of water and other associated functional groups. Thermogravimetric analysis support the presence of $7 \mathrm{H}_{2} \mathrm{O}$ molecules associated with holmium oxalate crystal lattice. The thermal decomposition in the nitrogen atmosphere leads to the formation of holmium oxide as the final product.
\end{abstract}

Keywords: Holmium Oxalate Heptahydrate; Single Rystals; X-Ray Diffraction; Thermogravimetric Analysis

\section{Introduction}

Rare-earth elements are essential components of modern technology and have numerous applications such as in data storage devices, lasers, phosphors for advanced displays, luminescent, catalysts and permanent magnets [1-8]. Mixed rare-earth oxalates have been used as precursors for preparing important dielectric and magnetic materials. For instance Samarium doped spinel Mg-Cd ferrites have been prepared by oxalate co-precipitation method [9]. The preparation of $\mathrm{PbTiO}_{3}$, a piezoelectric and ferroelectric material, has been achieved by oxalate precursor method [10]. The synthesis of nanocrystalline rare-earth oxides are currently a priority area in materials. The most important functional materials based on rare-earth oxides are phosphors [11], catalysts [12] etc. One of the efficient methods for preparation of rare-earth oxides is from oxalate precipitation [13]. The advantage of co-precipitation followed by thermal decomposition is that it normally avoids high temperature treatments. Pure and mixed rareearth oxides have been prepared at temperatures as low as $800^{\circ} \mathrm{C}$ [14]. Rare-earth coordination compounds have also an ability to incorporate both photoluminescent centres and magnetic properties, making them ideal for developing new multifunctional materials [15]. The fluorescence of some rare-earth oxalates suggest that these materials can be used for optical applications [16].

Due to extremely poor solubility in water and in organic solvents, the single crystals of rare-earth oxalates have been gown by gel diffusion method [17-22]. In gel diffusion method the corresponding reactants are allowed to react at very slow rate, thereby minimizing the chances of fast precipitation which often results in the formation amorphous precipitates. The present paper reports on the growth and characterization of single crystals of holmium oxalate heptahydrate (HOP).

\section{Experimental Procedure}

Crystallization of holmium oxalate heptahydrate crystals was achieved using the single gel diffusion technique [23]. The crystallizer consisted of a single glass tube of length $20 \mathrm{~cm}$ and diameter $2.5 \mathrm{~cm}$. Different experiments were carried out to grow single crystals of holmium oxalate from organic agar gel. The agar gel was prepared by dissolving $1 \% \mathrm{w} / \mathrm{v}$ of extra pure agar powder in triply deionised water at $80^{\circ} \mathrm{C}$. The agar solution was then mixed with desired concentration of oxalic acid $(0.25$, $0.5,0.75$ and $1 \mathrm{M}$ ). The agar and oxalic acid solutions were mixed in various proportions by volume. The mixed solution was then transferred into several glass tubes. After setting of the gel, an aqueous solution of holmium nitrate pentahydrate with concentrations $0.25,0.5,0.75$ and $1 \mathrm{M}$ was carefully poured over the set gel. The tubes were allowed to stand for a period of about two weeks, after which well faceted hexagonal shaped single crystals of HOP grew inside the agar gel. The slow diffusion of $\mathrm{Ho}^{3+}$ ions through the narrow pores of the agar gel lead 
to reaction between these ions and the oxalate ions $\left(\mathrm{C}_{2} \mathrm{O}_{4}\right)^{-2}$ present in the gel as lower reactant. The reaction leads to the formation of single crystals of HOP. All the experiments were carried out at an ambient temperature of about $27^{\circ} \mathrm{C}$.

Powder X-ray diffraction analysis of HOP crystals were obtained using a Bruker D8 advance X-ray diffracttometer with $\mathrm{Cu} \mathrm{K} \alpha$ radiation $(\lambda=1.5406 \AA)$, The Carbon and hydrogen contents in the grown crystals were determined by using Vario-EL III CHNS-analyzer. An energy dispersive spectrometer (OXFORD ISIS-300 system) attached to a scanning electron microscope JEOL JSM-5800 was used to identify the presence of holmium and oxygen. The FT-IR spectra of the grown crystals in the wavenumber range of $400-4000 \mathrm{~cm}^{-1}$ were recorded on a Bruker Vector-22 spectrometer using $\mathrm{KBr}$ pellet technique. The thermal behaviour (TGA) of the crystals was recorded on a Perkin Elmer, Diamond TG/DTA thermal analyzer in $\mathrm{N}_{2}$ atmosphere at a heating rate of $10^{\circ} \mathrm{C} / \mathrm{min}$. The morphology of the grown crystals was examined using an optical microscope.

\section{Results and Discussion}

\subsection{Growth}

A number of experiments were performed to obtain the optimum and reproducible conditions for growth of single crystals of holmium oxalate in agar gel. The growth parameters such as concentration of upper and lower reactants and gel concentration were changed in order to see their effect on the quality of the crystals. The $\mathrm{pH}$ of the agar-oxalic acid solution was adjusted to an initial value of 1.5 by adding few drops of dilute nitric acid to the solution. At this a negligible precipitation occurred at the gel/solution interface upon pouring of upper reactant and after a period of about two weeks, the single crystals of holmium oxalate were observed to grow inside the gel column. Single crystals with well developed habit faces were obtained under the following conditions: gel $\mathrm{pH} 2$, gel concentration $1 \% \mathrm{w} / \mathrm{v}$, oxalic acid concentration 0.5 $\mathrm{M}$, holmium nitrate pentahydrate concentration $0.5 \mathrm{M}$, temperature $27^{\circ} \mathrm{C}$.

Figure 1 shows single crystals of HOP growing in agar gel in a crystallizer. Figure 2(a) shows a typical single crystal of HOP under an optical microscope and Figure 2(b) is the schematic diagram illustrating the general morphology and the habit faces of HOP single crystals grown in the agar gel. The morphology as depicted in Figure 2(b) was obtained by using the program KrystShaper (http://www.jcrystal.com/products/krystalshaper/). The single crystals of HOP have the general hexagonal morphology with (010), (011), (0-11) and (001) as habit faces with (100) face being most prominent.

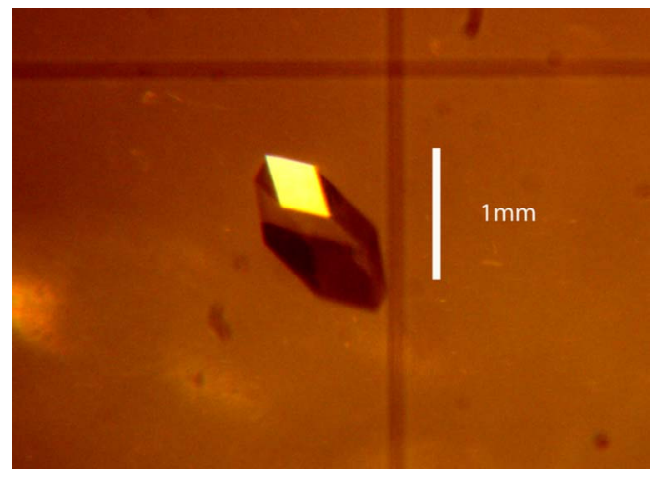

Figure 1. A typical single crystal of HOP growing in a crystallizer in agar gel medium.

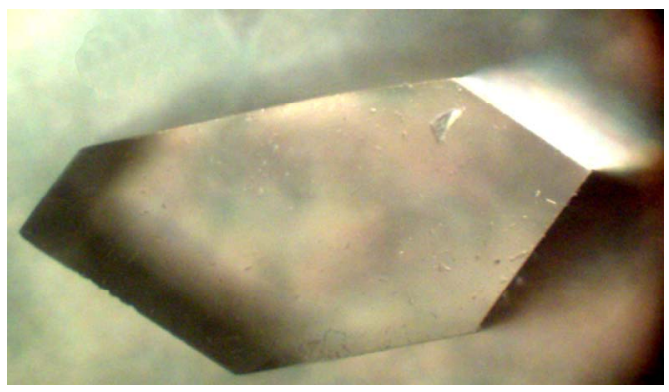

(a)

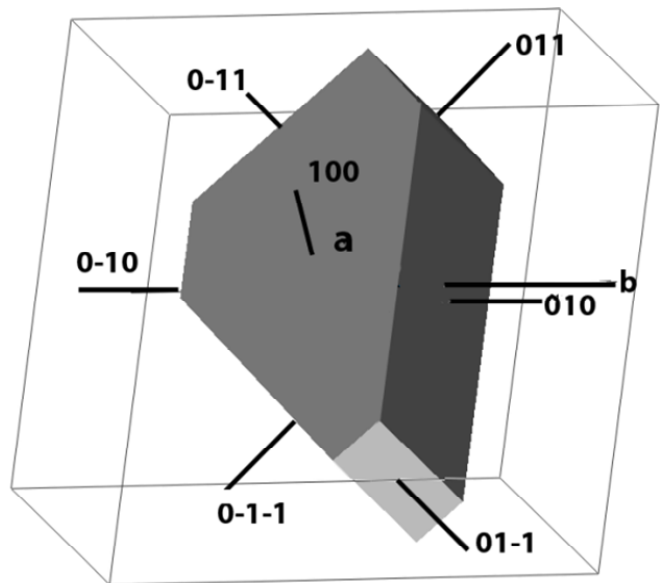

(b)

Figure 2. (a) An optical photograph of a typical single crystal of HOP illustrating the general morphology of crystals; (b) Schematic representation of general morphology of HOP crystals showing the prominent habit faces.

\subsection{Characterization}

\subsubsection{Powder X-Ray Diffraction}

The powder diffractogram of HOP crystals is shown in Figure 3. The occurrence of highly resolved peaks at specific Bragg angles indicates that the holmium oxalate heptahydrate is a crystalline solid. The powder x-ray diffraction pattern of HOP was analyzed by using the indexing program DICVOL04 [24]. A monoclinic unit cell was found with space group $\mathrm{P} 2 / \mathrm{c}$ and the cell parameters 
as: $a=12.197 \AA, b=11.714 \AA, c=6.479 \AA, \alpha=90^{\circ}, \beta=$ $120.12^{\circ}, \gamma=90^{\circ}, V=799.6 \AA^{3}$.

\subsubsection{Elemental Analysis}

Figure 4 shows the EDAX spectrum of a typical single crystal of HOP. The presence of holmium is clearly depicted in the spectrum. Since holmium oxalate heptahydrate is a rare earth coordination compound with oxalic acid as a ligand, therefore, carbon and hydrogen analysis was carried out to determine the percentage composition of carbon and hydrogen. Table 1 shows the results of carbon-hydrogen analysis.

The percentage composition of $\mathrm{C}$ and $\mathrm{H}$ as determined experimentally by $\mathrm{CHN}$ analysis together with the EDAX results suggest that the chemical formula of the single crystals of $\mathrm{HOP}$ to be $\mathrm{Ho}_{2}\left(\mathrm{C}_{2} \mathrm{O}_{4}\right)_{3} \cdot 7 \mathrm{H}_{2} \mathrm{O}$. The percentage composition of $\mathrm{C}$ and $\mathrm{H}$ in the proposed formula agrees well with the corresponding values which were determined experimentally as shown in Table 1. The presence of $7 \mathrm{H}_{2} \mathrm{O}$ molecules associated with the HOP crystals is further supported by the thermogravimetric analysis (TGA). Figure 5 shows the TGA curve of $\mathrm{HOP}$ in the temperature range of $28^{\circ} \mathrm{C}$ to $1050^{\circ} \mathrm{C}$. It is clear from the curve that the single crystals of HOP undergo a weight loss of about $18.1 \%$ in the temperature

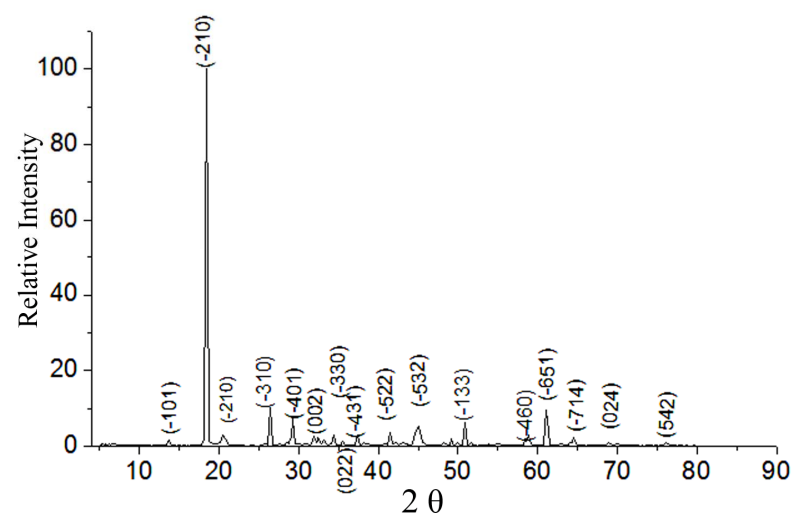

Figure 3. Powder X-ray diffraction pattern of HOP crystals.

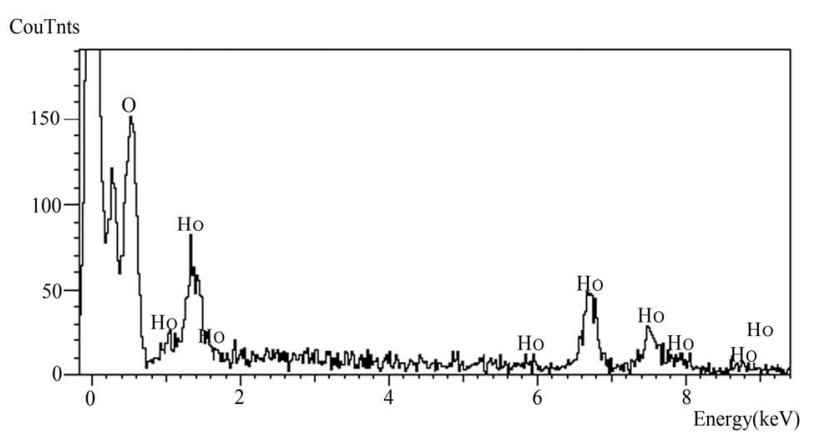

Figure 4. EDAX spectrum of a typical single crystal holmium oxalate heptahydrate.
Table 1. Percentage composition of carbon and hydrogen in the grown crystals of HOP.

\begin{tabular}{ccc}
\hline Element & $\begin{array}{c}\text { Percentage } \\
\text { composition } \\
\text { (Experimental) }\end{array}$ & $\begin{array}{c}\text { Percentage } \\
\text { composition } \\
\text { (Calculated) }\end{array}$ \\
\hline Carbon & 9.76 & 10.01 \\
Hydrogen & 1.89 & 1.959 \\
\hline
\end{tabular}

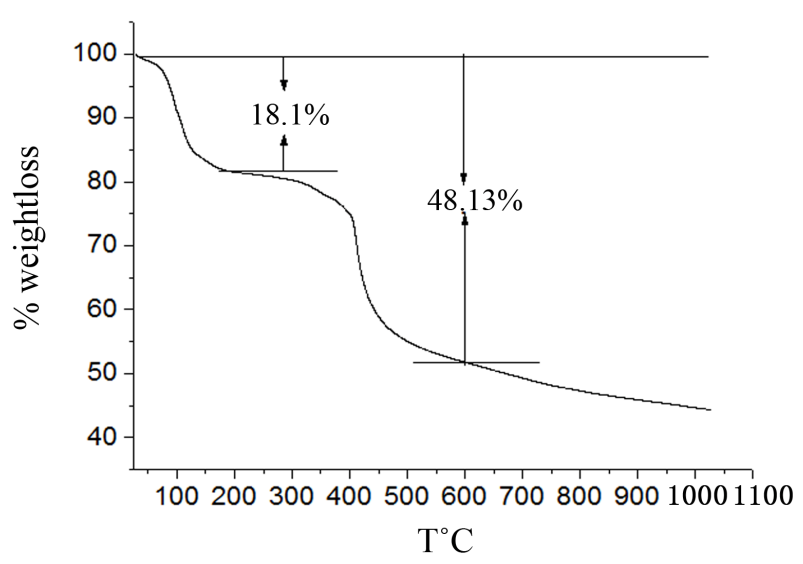

Figure 5. TGA curve of holmium oxalate heptahydrate.

range of $28^{\circ} \mathrm{C}$ to $200^{\circ} \mathrm{C}$. The calculated weight loss as per the proposed formula: $\mathrm{Ho}_{2}\left(\mathrm{C}_{2} \mathrm{O}_{4}\right)_{3} \cdot 7 \mathrm{H}_{2} \mathrm{O}$, is $17.5 \%$. The formation of mixed holmium oxide $\mathrm{Ho}_{2} \mathrm{O}_{3}$ as a final product was also confirmed from the TG curve. The calculated weight loss for the formation of $\mathrm{Ho}_{2} \mathrm{O}_{3}$ from the starting compound $\mathrm{Ho}_{2}\left(\mathrm{C}_{2} \mathrm{O}_{4}\right)_{3} \cdot 7 \mathrm{H}_{2} \mathrm{O}$ is $47.5 \%$ whereas the experimentally observed weight loss in the temperature range $28^{\circ} \mathrm{C}-600^{\circ} \mathrm{C}$ is $48.13 \%$. Thus, at a temperature of about $600^{\circ} \mathrm{C}$ holmium oxide is formed as a final product. The formation of erbium oxide from the thermal decomposition of erbium oxalate hexahydrate at $600^{\circ} \mathrm{C}$ is reported in the literature [25].

\subsubsection{Fourier Transform Infra Red Spectroscopy}

Figure 6 shows the FT-IR spectrum of HOP crystals in the wave number range $400-4000 \mathrm{~cm}^{-1}$. The presence of broad band centred at about $3325.25 \mathrm{~cm}^{-1}$ indicates that the grown material has water of crystallization. The absorption at about $1627.35 \mathrm{~cm}^{-1}$ correspond to the asymmetric stretch $v_{\mathrm{a}}(\mathrm{C}=\mathrm{O})$. The well pronounced peaks at $1361.29 \mathrm{~cm}^{-1}$ and $1319.62 \mathrm{~cm}^{-1}$ correspond to symmetric stretches $\left[v_{\mathrm{s}}(\mathrm{CO})+v(\mathrm{CC})\right]$ and $\left[v_{\mathrm{s}}(\mathrm{CO})+\delta(\mathrm{O}-\mathrm{C}=\mathrm{O})\right]$ respectively [26,27]. The sharp IR peak observed at $808.81 \mathrm{~cm}^{-1}$ is due to the combined effect of in-plane bending motion $\delta(\mathrm{O}-\mathrm{C}=\mathrm{O})$ [28] and the presence of a metal-oxygen bond $v(\mathrm{MO})$. The absorption at 487.82 $\mathrm{cm}^{-1}$ is due to the ring deformation plus the bending a metal-oxygen bond $v(\mathrm{MO})$. The absorption at 487.82 $\mathrm{cm}^{-1}$ is due to the ring deformation plus the bending mode $\delta(\mathrm{O}-\mathrm{C}=\mathrm{O})[29]$. The assignment of some selected 


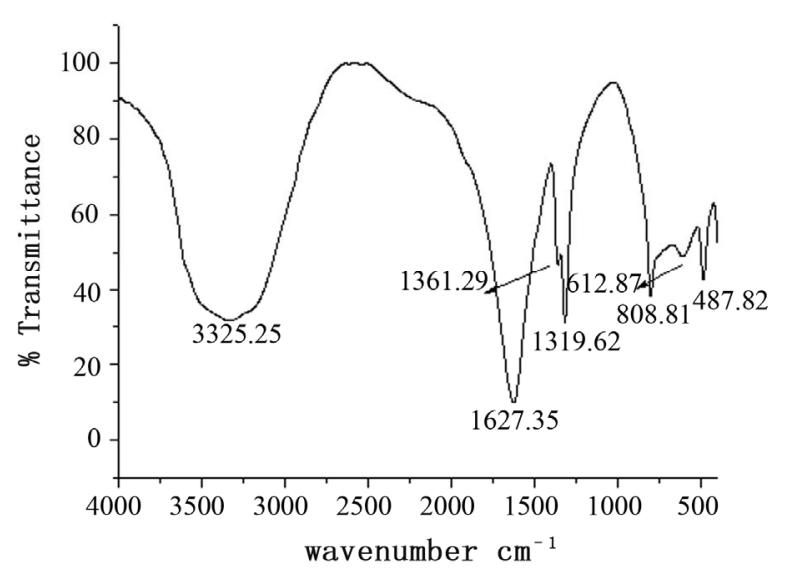

Figure 6. FTIR spectrum of holmium oxalate heptahydrate.

Table 2. Assignment of some selected FT-IR wavenumbers $\left(\mathrm{cm}^{-1}\right)$ of HOP.

\begin{tabular}{cc}
\hline Wave number $\mathrm{cm}^{-1}$ & Band/Peak Assignments \\
\hline 3325.25 & $v_{\mathrm{a}}(\mathrm{OH})$ \\
1627.35 & $v_{\mathrm{a}}(\mathrm{C}=\mathrm{O})$ \\
1361.29 & $v_{\mathrm{s}}(\mathrm{CO})+v(\mathrm{CC})$ \\
1319.62 & $v_{\mathrm{s}}(\mathrm{CO})+\delta(\mathrm{O}-\mathrm{C}=\mathrm{O})$ \\
808.81 & $\delta(\mathrm{O}-\mathrm{C}=\mathrm{O})+v(\mathrm{MO})$ \\
487.82 & $\delta(\mathrm{O}-\mathrm{C}=\mathrm{O})$ \\
\hline
\end{tabular}

absorption band/peaks observed in the FT-IR spectrum of LNO is given in Table 2. The FT-IR spectroscopic results of HOP crystals confirm the presence of functional groups associated with oxalate ligands.

\section{Conclusion}

The single crystals of holmium oxalate heptahydrate: $\mathrm{Ho}_{2}\left(\mathrm{C}_{2} \mathrm{O}_{4}\right)_{3} \cdot 7 \mathrm{H}_{2} \mathrm{O}$ were grown by single gel diffusion technique using organic agar gel as a medium of growth. The crystals are transparent and well faceted with (010), (011), (0-11) and (001) as habit faces and belong to monoclinic system with space group $\mathrm{P} 2{ }_{1} / \mathrm{c}$. The coordination of oxalate ligand with the holmium is confirmed by the presence of specific absorption bands and peaks in the FTIR spectrum of the grown crystals. Thermogravimetric analysis also confirms the association of seven water molecules with the crystal lattice of holmium oxalate heptahydrate.

\section{REFERENCES}

[1] T. J. Kane and R. L. Byer, "Monolithic, Unidirectional
Single-Mode Nd:YAG Ring Lase," Optics Letters, Vol. 10, No. 2, 1985, pp. 65-67. doi:10.1364/OL.10.000065

[2] C. R. Ronda, T. Jüstel and J. Nikol, "Rare Earth Phosphors: Fundamentals and Application," Journal of Alloys and Compounds, Vol. 275-277, 1998, pp. 669-676. doi:10.1016/S0925-8388(98)00416-2.

[3] R. J. H. Voorhoeve, J.P. Remeika, P. E. Freeland and B. T. Matthias, "Rare-Earth Oxides of Manganese and Cobalt Rival Platinum for the Treatment of Carbon Monoxide in Auto Exhaust," Science, Vol. 177, No. 4046, 1972, pp. 353-354. doi:10.1126/science.177.4046.353

[4] M. Sagawa, S. Fujimura, N. Togawa, H. Yamamoto and Y. Matsuura, "New Material for Permanent Magnets on a Base of Nd and Fe," Journal of Applied Physics, Vol. 55, No. 6, 1984, pp. 2083-2087. doi:10.1063/1.333572.

[5] Y. Heesun, S. Sooyeon, A. Mostafa and P. H. Holloway, "Synthesis and Luminescent Properties of Rare EarthDoped YVO4 Nanocrystalline Powders," Journal of Ceramic Processing Research, Vol. 8, No. 4, 2007, pp. 256260.

[6] E. Garskaite, M. Lindgren, M. Einarsrud and T. Grande, "Luminescent Properties of Rare Earth (Er, Yb) Doped Yttrium Aluminium Garnet Thin Films and Bulk Samples Synthesized by an Aqueous Sol-Gel Technique," Journal of the European Ceramic Society, Vol. 30, 2010, pp. 1707-1715. doi:10.1016/j.eurceramsoc.2010.01.001

[7] K. Meier, R. Cardoso-Gil, W. Schnelle, H. Rosner, U. Burkhardt and U. Schwarz, "Thermal, Magnetic, Electronic, and Superconducting Properties of Rare-Earth Metal Pentagermanides REGe5 $(\mathrm{RE}=\mathrm{La}, \mathrm{Nd}, \mathrm{Sm}, \mathrm{Gd})$ and Synthesis of TbGe5," Zeitschrift für Anorganische und Allgemeine Chemie, Vol. 636, No. 8, 2010, pp. 14661473. doi:10.1002/zaac.201000065.

[8] R. Peters, K. Petermann and G. Huber, "Growth Technology and Laser Properties of Yb-Doped Sesquioxides," In: P. Capper and P. Rudolph, Eds., Crystal Growth Technology: Semiconductors and Dielectrics, Wiley-VCH Verlag GmbH \& Co. KGaA, Weinheim, 2010, p. 267.

[9] A. B. Gadkaria, T. J. Shinde and P. N. Vasambekar, "Magnetic Properties of Rare Earth Ion $\left(\mathrm{Sm}^{3+}\right)$ Added Nanocrystalline Mg-Cd Ferrites, Prepared by Oxalate CoPrecipitation Method" Journal of Magnetism and Magnetic Materials, Vol. 322, No. 24, 2010, pp. 3823-3827. doi:10.1016/j.jmmm.2010.06.021

[10] M. A. El-F. Gabal, "Synthesis and Characterization of Nanocrystalline $\mathrm{PbTiO}_{3}$," Industrial \& Engineering Chemistry Research, Vol. 50, No. 24, 2011, pp. 13771-13777. DOI: $10.1021 / \mathrm{ie} 202255 \mathrm{~g}$

[11] J. Blanusa, N. Jovic, T. Dzomic, B. Antic, A. Kremenovic, M. Mitric and V. Spasojevic, "Magnetic Susceptibility and Ordering of $\mathrm{Yb}$ and $\mathrm{Er}$ in Phosphors $\mathrm{Yb}, \mathrm{Er}: \mathrm{Lu}_{2} \mathrm{O}_{3}$," Optical Materials, Vol. 30, 2008, pp. 1153-1156. doi:10.1016/j.optmat.2007.05.039

[12] S. Sato, R. Takahashi, M. Kobune and H. Gotoh, "Basic Properties of Rare-Earth Oxide," Applied Catalysis A: General, Vol. 356, No. 1, 2009, pp. 57-63. doi:10.1016/j.apcata.2008.12.019. 
[13] M. A. Gabal, S. A. Hameed and A. Y. Obaid, "CoTiO via Cobalt Oxalate- $\mathrm{TiO}_{2}$ Precursor. Synthesis and Characterization," Materials Characterization, Vol. 71, 2012, pp. 87-94. doi:10.1016/j.matchar.2012.06.009

[14] C. Artini, G. A. Costa and R. Masini, "Study of the Formation Temperature of Mixed $\mathrm{LaREO}_{3}(\mathrm{RE} \equiv \mathrm{Dy}, \mathrm{Ho}, \mathrm{Er}$, $\mathrm{Tm}, \mathrm{Yb}, \mathrm{Lu}$ ) and $\mathrm{NdGdO}_{3}$ Oxides," Journal of Thermal Analysis and Calorimetry, Vol. 103, No. 1, 2011, pp. 1721. doI:10.1007/s10973-010-0973-8

[15] K. Liua, G. Jia, Y. Zheng, Y. Song, M. Yang, Y. Huang, L. Zhang and H. You, "Room-Temperature Synthesis and Luminescence Properties of $\mathrm{Eu}^{3+} / \mathrm{Tb}^{3+}$-Doped $\mathrm{La}(1$, 3,5-BTC) $\left(\mathrm{H}_{2} \mathrm{O}\right)_{6}$," Inorganic Chemistry Communications, Vol. 12, 2009, pp. 1246-1249. doi:10.1016/j.inoche.2009.09.033

[16] P. K. Gallagher, F. Schrey and Prescott, "Study of the Thermal Decomposition of Europium(III) Oxalate Using the Moessbauer Effect," Inorganic Chemistry, Vol. 9, 1970, pp. 215-219. doi:10.1021/ic50084a004

[17] B. Want, "Single Crystal Growth and Characterization of Lanthanum-Neodymium Oxalate Octahydrate," Journal of Crystal Growth, Vol. 335, No. 1, 2011, pp. 90-93. doi:10.1016/j.jcrysgro.2011.08.020.

[18] M. V. John and M. A. Ittyachen, "Growth and Characterization of Mixed Cerium Lanthanum Oxalate Decahydrate Crystals in Silica Gel," Crystal Research and Technology, Vol. 36, 2001, pp. 141-146. doi:10.1002/1521-4079(200102)36:2<141::AID-CRAT14 1>3.0.CO;2-0

[19] A. M. E. Raj, D. D. Jayanthi, V. B. Jothy, M. Jayachandran and C. Sanjeeviraja, "Growth Aspects of Barium Oxalate Monohydrate Single Crystals in Gel Medium," Crystal Research and Technology, Vol. 43, No. 12, 2008, pp. 1307-1313. doi:10.1002/crat.200800038

[20] C. Joseph, G. Varughese and M. A. Ittyachen, "Growth and Characterization of Mixed Neodymium Praseodymium Oxalate Decahydrate Crystals in Silica Gel," Crystal
Research and Technology, Vol. 30, No. 2, 1995, pp. 159164. doi:10.1002/crat.2170300203.

[21] G. Varghese, M. A. Ittyachen and J. Issac, "Studies on $\mathrm{La}_{1-\mathrm{x}} \mathrm{Cu}_{\mathrm{x}} \cdot 3 \mathrm{C}_{2} \mathrm{O}_{4} \cdot \mathrm{nH}_{2} \mathrm{O}$ Crystals Grown in Hydro-Silica Gel," Crystal Research and Technology, Vol. 25, No. 7, 1990, pp. 153-159. doi:10.1002/crat.2170250722,

[22] I. Korah, C. Joseph and Ittyachan, "Growth and Characterisation of Gadolinium Samarium Oxalate Single Crystals," Crystal Research and Technology, Vol. 42, No. 10, 2007, pp. 939-942. doi:10.1002/crat.200710962.

[23] H. K. Henisch, "Crystals in Gels and Liesegang Rings," Cambridge University Press, Cambridge, 1988.

[24] A. Boultif and D. Louer, "Powder Pattern Indexing with the Dichotomy Method," Journal of Applied Crystallography, Vol. 37, No. 5, 2004, pp. 724-773. doi:10.1107/S0021889804014876.

[25] B. A. A. Balboul, "Thermal Decomposition Study of Erbium Oxalate Hexahydrate," Thermochimica Acta, Vol. 351, No. 1, 2000, pp. 55-60. doi:10.1016/S0040-6031(00)00353-1

[26] K. Nakamoto, "Infra Red and Raman Spectra of Inorganic and Coordination Compounds," 6th Edition, John-Wiley \& Sons, Hoboken, 2009, pp. 766-773.

[27] G. Socrates, "Infrared and Raman Characteristic Group Frequencies: Table and Charts," 3rd Edition, John Wiley \& Sons Inc., New York, 2004, p. 287.

[28] J. Fujita, A. E. Martell and K. Nakamoto, "Infrared Spectra of Metal Chelate Compounds. VI. A Normal Coordinate Treatment of Oxalato Metal Complexes," Journal of Chemical Physics, Vol. 36, No. 2, 1962, pp. 324-332. doi:10.1063/1.173250.

[29] J. R. Ferraro, "Low Frequency Vibrations of Inorganic and Co-ordination Compounds," Plenum Press, New York, 1971. 